\title{
A (I)MATERIALIDADE DOS CAMINHOS DE JACOBINA: A PRODUCÃO DOS ESPACOS TURÍSTICOS DA CIDADE ATRAVÉS DOS LUGARES DE MEMÓRIA
}

Daniel Luciano Gevehr ${ }^{1}$

\begin{abstract}
RESUMO
O artigo analisa as representações simbólicas construídas sobre o conflito Mucker (Colônia Alemã de São Leopoldo, 1868-1874) e como essas se manifestam materialmente nos diferentes espaços que procuram lembrar dos fatos e personagens que marcaram a história do conflito. Detemo-nos, aqui, na análise do processo que envolve a produção e a difusão de representações sobre o episódio e que acabaram se materializando na construção de diferentes lugares de memória, localizados em diferentes espacialidades do atual município onde ocorreu o conflito, que é Sapiranga (RS). Pretendemos discutir os diferentes condicionantes e propósitos que estiveram presentes nessa construção e como esses foram alvo de (re)interpretações em diferentes épocas, produzindo, assim, os imaginários sociais sobre o episódio em questão. Discute-se, ainda, a relação da produção desses lugares de memória, que lembram dos Mucker, com o propósito de desenvolver o turismo, a partir da criação dos Caminhos de Jacobina, que apresenta aos visitantes os lugares que buscam perpetuar a(s) memória(s) construídas - e muitas vezes impostas - sobre os Mucker.
\end{abstract}

Palavras-chave: Mucker. Lugares de Memória. Turismo histórico-cultural.

\section{ABSTRACT}

The present article analyzes the symbolic representations built around the Mucker conflict (German-descent Colony of São Leopoldo, 1868-1874) and how these manifest materially in different spaces that aim at remembering facts and characters that branded the history surrounding the referred conflict. We focus at analyzing the process in which the production and the spreading of the representations around the episode is involved, which ended up getting materialized in the building of different places of memory located in several areas around the town where the conflict took place, namely the city of Sapiranga (RS).

\footnotetext{
${ }^{1}$ Doutor em História pela Universidade do Vale do Rio dos Sinos (Unisinos)/RS. Professor das Faculdades Integradas de Taquara (Faccat)/RS e do Programa de Pós-Graduação em Desenvolvimento Regional da Faccat e do Instituto Superior de Educação Ivoti (ISEI)/RS. danielgevehr@hotmail.com
} 
We intend to discuss the several conditions and purposes underlying such construction as well as to the extent to which they became the target of (re)interpretations at different times, producing the social imaginaries on the episode under study. We also discuss the relationship established by the production of these places of memory, which remind us of the Mucker, in order to develop tourism by taking the creation of Caminhos de Jacobina (Jacobina's Pathways) as a starting point, for it introduces such places to those wishing to make memories built - and more often than not, imposed - on the Mucker everlasting.

Keywords: Mucker. Places of memory. Historical-cultural tourism.

\section{CONSIDERAÇÕES INICIAIS}

Tendo como ponto de partida a questão que envolve a produção da memória e sua vinculação com os lugares de memória - e sua materialidade simbólica -, buscamos investigar como, em diferentes épocas e contextos, se produziram imagens e idealizações sobre o movimento Mucker². Concentramos nossa análise na compreensão dos mecanismos simbólicos que estiveram envolvidos na produção dos lugares de memória sobre os Mucker em Sapiranga (RS) e como esses acabaram sendo apropriados pela municipalidade na perspectiva de desenvolver o turismo como uma alternativa de desenvolvimento regional.

O conflito Mucker, que dá origem a nossa discussão, é um dos movimentos messiânicos ainda menos discutidos pela historiografia brasileira ${ }^{3}$, mas que revela, em nossa interpretação, dois aspectos singulares, o que o torna ainda mais relevante novos estudos sobre o tema. Primeiramente, por ter sido o único movimento messiânico brasileiro que ocorreu em ambiente protestante; em segundo, por ser liderado por uma mulher.

Assim, inicialmente se faz necessária uma breve contextualização sobre os elementos centrais que estiveram envolvidos no conflito, a qual nos permitirá melhor compreender os propósitos de nossa discussão, que se concentra no entendimento da produção das representações simbólicas sobre os Mucker, que se manifestam, nos dias atuais, por meio daquilo que Nora (1993) identificou como lugares de memória.

O conflito Mucker (1868-1874) marcou de forma definitiva a história do atual município de Sapiranga (RS), no qual ocorreu o conflito e que, no século XIX, integrava a Antiga Colônia Alemã de São Leopoldo, fundada em 1824 por D. Pedro I. O conflito, de caráter messiânico, ocorreu em um ambiente de muitas transformações econômicas e sociais do século XIX, em especial no que diz respeito à política imigratória para o sul do Brasil e, acabou sendo alvo, após seu desfecho, de inúmeras interpretações.

\footnotetext{
${ }^{2} \mathrm{O}$ termo Mucker tem origem na língua alemã e pode significar santarrão, beato, fanático religioso. Nesse caso, foi empregado para identificar o grupo liderado por Jacobina no Ferrabraz, dando, assim, um sentido pejorativo ao grupo.

${ }^{3} \mathrm{Na}$ historiografia mais recente, é notável a preocupação com estudos que se propõem a discutir o processo de produção da memória sobre os movimentos messiânicos brasileiros, como são os casos dos episódios de Canudos e Contestado. Observamos, nesse caso, uma busca, cada vez maior, em analisar esses episódios a partir de novas problemáticas, que vinculam os fatos e personagens associados a eles com a produção da memória e também dos lugares de memória, tendo em vista o desenvolvimento do turismo nos lugares associados à história.
} 
Jacobina Mentz Maurer e seu marido João Jorge Maurer são apontados como protagonistas desse movimento, sendo acusados, por parte dos moradores da Colônia e pelas autoridades, de praticar curandeirismo e cultos em sua casa, que ficava nas imediações do morro Ferrabraz. Essas práticas eram associadas ao ambiente de fanatismo religioso que teria se criado no Ferrabraz, fazendo com que as autoridades tomassem ações, no sentido de acabar com o grupo, que havia se constituído em volta da líder Jacobina. O desfecho disso se deu em 1874, quando as forças imperiais acabaram com o grupo que se reunia ao pé do morro Ferrabraz, onde também ficava a casa de Jacobina e onde se realizavam seus cultos. O conflito resultou em uma série de mortos de ambos os lados do conflito.

Tomando os diferentes aspectos históricos que estiveram envolvidos no conflito, detemo-nos, inicialmente, na análise das imagens construídas e difundidas sobre Jacobina Maurer através da fotografia, do cinema, da pintura, e especialmente da monumentalidade, bem como da construção dos lugares de memória. Destaca-se, nesse, processo a vinculação que cada uma delas apresenta com o seu contexto de produção e os interesses dos diferentes grupos sociais que as forjaram. Atentamos, ainda, para o processo de ressignificação dessas imagens e representações ${ }^{4}$, identificando as transformações significativas de que foram alvo ao longo do período que compreende o final do século XIX até os dias atuais. Destacamos, sobretudo, o processo de manipulação da memória e dos sentimentos coletivos da comunidade em que o episódio ocorreu, evidenciado na eleição dos símbolos e dos lugares de memória da cidade de Sapiranga (RS) por meio dos quais se deu a materialização dessas imagens e dos sentimentos coletivos em relação aos Mucker.

Inicialmente, a difusão de determinadas representações sobre os Mucker e sobre sua líder Jacobina ocorreu através da publicação, em 1906, da obra Os Mucker (1906), por Ambrósio Schupp, um jesuíta alemão que chegou ao Brasil em 1874, mesmo ano do desfecho do conflito. Deve-se principalmente ao conteúdo de sua obra a construção de um imaginário essencialmente negativo em relação ao grupo liderado por Jacobina, o que acabou se difundindo entre a população. Mesmo com estudos posteriores, que procuraram dar outras versões sobre o conflito (como os de Leopoldo Petry, em 1957, Janaína Amado, em 1976, João Guilherme Biehl, em 1991 e Maria Amélia Dickie, em 1996), os Mucker continuaram sendo conhecidos pela comunidade sapiranguense como um grupo de fanáticos religiosos até o início do século XXI.

A ausência de fontes documentais produzidas pelo próprio grupo fez com que, durante muito tempo, a única versão dos fatos fosse a presente nos autos dos processos judiciais e nas fontes orais do lado daqueles que derrotaram os Mucker. Daí ser possível falar de uma ausência de "voz" por parte dos vencidos, que não tiveram a oportunidade de "contar" a sua própria versão dos fatos. Outro fator que, em nossa análise, julgamos

\footnotetext{
${ }^{4}$ Não desconhecemos a diversidade de abordagens sobre as representações sociais, contudo valemo-nos, especialmente, dos estudos realizados por Pierre Bourdieu, Roger Chartier e Bronislaw Baczko. Consideramos também extremamente válida a observação feita pela historiadora francesa Denise Jodelet (2001, p. 3) de que "elas [as representações sociais] expressam aqueles (indivíduos ou grupos) que as forjam e dão uma definição específica ao objeto por elas representado. Estas definições partilhadas pelos membros de um grupo constroem uma visão consensual da realidade para esse grupo. Esta visão, que pode entrar em conflito com a de outros grupos, é um guia para as ações e trocas cotidianas - trata-se das funções e da dinâmica sociais das representações".
} 
essencial é a ausência de imagens ${ }^{5}$ que materializem os personagens ou até mesmo o cenário na época do conflito, o que torna o grupo - e, de forma especial, sua líder, Jacobina - mais enigmático.

Além da produção historiográfica existente sobre o conflito e da veiculação de determinadas imagens e representações sobre sua líder, precisamos observar o processo que envolveu a ressignificação do episódio ao longo das décadas que se sucederam ao seu desfecho. A própria imprensa foi, nesse sentido, um importante veículo de difusão de imagens e representação sobre os Mucker, que acabou reforçando o imaginário fanatizado e unilateral sobre os fatos ocorridos no morro Ferrabraz. Exemplo concreto dessas manifestações, que acabaram reforçando o imaginário negativo em relação aos Mucker, foi a própria imprensa sapiranguense, que, nas décadas de 1950 e 1960, publicou, através dos escritos de Leopoldo Sefrin, no Jornal O Ferrabraz ${ }^{6}$, uma série de reportagens sobre o episódio. Nela, os Mucker foram sempre apresentados como culpados, e Jacobina como a principal responsável pelas atrocidades ocorridas no Ferrabraz.

No sentido contrário da visão que apresenta o conflito como resultado do fanatismo religioso, observamos, na década de 1990, o início de um novo período das representações e idealizações construídas sobre os Mucker. Merece destaque nesse novo contexto a obra literária Videiras de Cristal, de Antônio Luiz de Assis Brasil. O romance histórico ${ }^{7}$ em questão abriu espaço, em nível estadual e nacional, para a discussão sobre

5 A única forma de registro que encontramos sobre a líder dos Mucker é uma fotografia, cuja veracidade é fortemente questionada, que apresenta Jacobina junto ao seu marido, João Jorge Maurer, conhecido como o curandeiro que realizava milagres de cura no Morro Ferrabraz, lugar de moradia do casal e onde realizavam suas atividades. A fotografia é apresentada na obra A Nova Face dos Mucker, de Moacyr Domingues, após exaustiva pesquisa documental (DOMINGUES, 1977, p. 7). Entretanto, sobre sua autenticidade, colocam-se várias dúvidas.

6 O nome escolhido para o jornal dos sapiranguenses - O Ferrabraz - foi uma forma de identificar a imprensa local com a comunidade, na medida em que o morro era conhecido dos sapiranguenses e fazia parte da paisagem local. O jornal foi fundado em 1 ㅇ de dezembro de 1949, por Guilherme José Powolny, nascido na Alemanha, no ano de 1904. Chegando em Sapiranga, Powolny fundou a Gráfica Sapiranga ao mesmo tempo em que foi diretor do jornal. O fato de ser estrangeiro obrigou-o, por motivos legais, a colocar - oficialmente - outra pessoa como proprietária de seu jornal. Para essa função, foi escolhido Leopoldo Luiz Sefrin, figura importante no meio social da cidade. O jornal procurava se mostrar como um veículo que procurava publicar as notícias de interesse coletivo da população de São Leopoldo, sendo essa sua filosofía estampada na capa das edições, sempre abaixo do nome do jornal. Na década de 1950, a tiragem do jornal alcançava entre 1500 e 2000 exemplares, a maioria com destino certo, uma vez que grande parte de seus leitores eram assinantes. Não temos informações precisas sobre o número de leitores do jornal. Todavia, sabemos que o número de exemplares ficava em torno de 1500, levando-nos a acreditar que o número de leitores não chegava a 5000 pessoas. Essas edições eram, em sua maioria, vendidas por assinatura e eram de circulação local para uma população que chegava a pouco mais de 12000 habitantes.

7 Identificamos, na narrativa de Assis Brasil, uma forte vinculação de Jacobina com o ambiente da Colônia Alemã e com os diferentes laços que a personagem estabeleceu no meio social recriado. Nesse sentido, destacamos que, embora o autor não tenha se proposto a "contar a história" de Jacobina, acabou contribuindo de forma decisiva - no contexto da década de 1990 em diante - para a difusão de um imaginário sobre a líder dos Mucker. É nessa perspectiva, de discutir a produção - e difusão - de uma nova imagem de Jacobina, associada não mais apenas ao fanatismo religioso e ao desregramento social, que inserimos a obra Videiras de Cristal. A Jacobina apresentada por Assis Brasil passava, através da literatura, a ter uma nova representação, muito mais positiva, que acabou se materializando no imaginário social e contribuindo para a (re)produção de uma nova memória sobre a líder dos colonos que haviam se organizado no morro Ferrabraz. 
o tema, algo que, de certa forma, ainda se mostrava bastante velado na região em que ocorreu o massacre. Observa-se, de fato, que as pessoas ainda tinham receio em falar sobre o tema na região. É precisamente a partir dessa fase que podemos falar em um amplo processo de ressignificação e de difusão de novas imagens e representações sobre os Mucker e especialmente sobre sua líder Jacobina.

O novo contexto do final do século XX e as novas perspectivas de desenvolvimento da região foram condicionantes significativos que nos permitem compreender como os Mucker foram alvo de ressignificações, que os colocaram não mais apenas na condição de culpados, mas em um processo que nos permite identificar a heroicização de sua líder e, consequentemente, do grupo por ela liderado.

Esse processo, de significativa transformação no âmbito da criação e da difusão de imagens sobre os Mucker, tornou-se mais evidente se observarmos o processo que envolveu a criação daquilo que Pierre Nora chama de lugares de memória. Esses lugares, que procuram marcar no tempo e no espaço os lugares dos Mucker foram alvo de manipulação e ressignificação, na medida em que os interesses presentes, especialmente no início do século XXI, associavam-se à ideia de projeção de Sapiranga no cenário nacional, especialmente através do filme $A$ Paixão de Jacobina ${ }^{8}$, produzido pela família Barreto em 2002.

Com o propósito de compreender o processo que envolveu a construção dos lugares de memória e a difusão de imagens e representações sobre os Mucker e sobre a líder Jacobina, atentamos para aquilo que Halbwachs (2004, p. 150) nos diz sobre os lugares de memória. Para ele, os lugares que percorremos nos fazem lembrar de fatos ocorridos no passado e, assim, contribuem para a construção da memória coletiva. A construção de monumentos, a denominação de lugares e a preocupação com a valorização de personagens do passado estão diretamente associadas a uma memória coletiva. Dessa forma, quando uma comunidade elege seus lugares de memória e também seus símbolos e heróis - que passam a representá-la -, pode-se perceber os condicionantes que estiveram envolvidos nesse processo de construção das representações.

As várias interpretações sobre os Mucker acabaram difundindo diferentes versões e, especialmente, definindo os "heróis" e os "culpados" do conflito. Em seu estudo sobre a difusão de imagens construídas sobre as mulheres do sul do Brasil, Joana Maria Pedro

\footnotetext{
8 Como sugere o título, o filme explorou a sensualidade e o fanatismo de sua personagem central, Jacobina Maurer. A "paixão", nesse caso, definia-se como o fanatismo religioso de Jacobina, cuja figura misturava sensualidade e nudez como expressão de sua entrega a Deus. Foi em meio a esse ritual que misturava fanatismo e sensualidade que Jacobina surge como personagem central do filme. Não podemos esquecer que se tratava de colonos que levavam uma vida bastante simples, assim como também eram suas casas, suas roupas e sua própria forma de falar, que não se comparava com as mostradas nas cenas de $A$ paixão de Jacobina. Isso nos leva crer que não houve preocupação com uma caracterização fiel do ambiente de época, mas a criação de um cenário que pudesse agradar aos espectadores. Nesse caso, o Ferrabraz apresentado no filme dos Barreto não foi o morro Ferrabraz "real", natural, com sua geografia recortada, com sua vegetação densa e de difícil acesso. Pelo contrário, o morro Ferrabraz de $A$ paixão de Jacobina foi o construído cenograficamente pelas mãos dos encarregados da montagem dos cenários, com casas perfeitamente pintadas e com tratamento paisagístico, agricultores alinhados e com roupas feitas de tecidos finos, cujas características em nada se assemelhavam às dos colonos da zona rural de São Leopoldo. O filme, por isso, construiu uma imagem ficcional do Ferrabraz e de seus moradores que em nada se associava ao ambiente vivido pelos Mucker.
} 
(2004, p. 283) mostra-nos como é praticamente impossível mensurarmos a apropriação de representações sociais. Para ela, pode-se tentar compreender e avaliar o impacto que as ideias difundidas causaram no meio social, embora seja impossível mensurar o grau de aceitação e da consequente internalização das ideias difundidas.

Outra questão importante em nossa pesquisa é a compreensão da construção dos símbolos associados aos fatos e aos personagens que marcaram a história de um grupo. Sobre essa questão, José Murilo de Carvalho (1990, p. 13) refere-se à associação existente entre construção dos imaginários sociais e a criação de diferentes símbolos para reforçar uma determinada visão sobre o passado. Para ele, a manipulação dos símbolos, das alegorias e até mesmo dos mitos criados sobre os personagens históricos nos ajuda a compreender a dinâmica que envolve a construção dos imaginários sociais. Já com relação à dinâmica que envolve a análise das representações sociais e a construção dos lugares de memória dos Mucker em Sapiranga, resgatamos aquilo que a historiadora Sandra Jatahy Pesavento (2002, p. 162) chama de ressemantização do tempo e do espaço. Para ela, é preciso considerar as transformações de caráter econômico, político, social e cultural, para que se torne possível a realização de uma leitura das representações sociais construídas num determinado contexto.

Assim, nossa análise parte do entendimento de que a constituição dos lugares de memória dos Mucker ocorreu - em um primeiro momento - como manifestação do sentimento de condenação e de rejeição aos Mucker. Exemplo dos efeitos dessa condenação foi a celebração de Genuíno Sampaio, comandante das tropas oficiais contrárias aos Mucker, como herói do conflito. Cabe ressaltar que, nesse processo de construção das representações sobre os Mucker, foram evocados sentidos, vivências e valores (PESAVENTO, 2002, p. 16) que deveriam ter significado para a comunidade. Nesse sentido, especialmente Jacobina foi apresentada como uma "mancha do passado", que devia ser lembrada como contraponto às aspirações da nova sociedade que se reorganizava após o desfecho do conflito e que tinha essa mulher como exemplo a não ser seguido.

A eleição desses dois personagens - como representantes dos dois lados do conflito - remete-nos à análise feita por Carvalho (1990), para quem o processo de "heroificação" inclui necessariamente a transmutação da figura real, a fim de torná-la arquétipo de valores ou aspirações coletivas, o que ocorreu com Jacobina e Genuíno. Além do papel desempenhado pelos testemunhos na construção de representações sobre os Mucker, deve-se ressaltar a importância - atribuída por Halbwachs (2004) - da constituição dos lugares de memória e sua significação. Tomando essas considerações como referência para nossa investigação, passamos a analisar os condicionantes envolvidos na construção dos lugares de memória dos Mucker em Sapiranga.

Fundamental para a análise do processo de construção dos lugares de memória é considerarmos o significado que esses diferentes lugares apresentam. É nesse sentido que destacamos a criação dos diferentes lugares de memória (monumentos, praças, instituições, etc.) dos Mucker em Sapiranga, município onde ocorreu o episódio no final do século XIX, seguindo a interpretação proposta por Françoise Choay (2001, p. 17), para quem os monumentos servem para advertir ou lembrar, tocando nas emoções.

De acordo com o historiador José Newton Coelho de Meneses (2004, p. 21), a 
"História e o Turismo Cultural, em seus limites interpretativos, monumentalizam eventos e musealizam existências". É nessa perspectiva ${ }^{9}$ que entendemos que os Mucker e Jacobina foram alvo de um amplo processo de ressignificação, em decorrência do projeto de desenvolvimento do turismo local, desencadeado no final do século XX e início do século XXI. Ao discutir os condicionantes que envolvem a construção dos pontos turísticos - de caráter histórico - em uma cidade, Meneses (2004, p. 14) afirma:

\begin{abstract}
Houve um tempo em que apenas heróis e figuras do Estado foram seres históricos dignos de percepção pelos intérpretes da construção histórica. A memória construída por esses historiadores a serviço ou não de estados e de governos ou de suas próprias ideologias políticas, religiosas ou morais, elegeu pontos do passado a iluminar e outros tantos a deixar no escuro. Aos incluídos, glória e honra (ou, às vezes, o contraponto disso, visto que a tradição do discurso descritivo exige, também o anti-herói). Aos excluídos, o esquecimento.
\end{abstract}

A transcrição acima torna claros os condicionantes envolvidos no processo de construção de lugares de memória que procuram destacar determinados personagens históricos. Fica evidente a exaltação dos personagens tidos como heróis, sua valorização através da materialização em monumentos e museus, da nomeação de lugares e até mesmo da criação de roteiros turísticos. Essa mesma situação descrita por Meneses pode ser encontrada em Sapiranga, especialmente no período do final do século XX e início do século XXI.

Se até meados do século XX a líder dos Mucker era identificada como uma mística fanática, de conduta moral condenável, a partir do final do século XX, Jacobina passará a ser associada ao cotidiano de dificuldades e de desigualdade social vivido pelos imigrantes alemães na colônia de São Leopoldo.

Suas qualidades morais e virtudes foram enfatizadas à medida que os Mucker eram reavaliados e não mais apontados como os únicos culpados pelo conflito. Isso tornou possível perceber os Mucker e o conflito como resultantes de uma série de fatores que envolveram a realidade da colônia alemã ao final do século XIX. A partir disso, os Mucker e sua líder passaram a ser apresentados nem como vítimas, nem como culpados, mas como um grupo que procurou lutar pela sobrevivência.

Demonstração dessa tentativa - a de criar lugares de memória - através da monumentalização, temos ainda no final do século XIX, quando se deu a construção do túmulo localizado no Cemitério do Bairro Amaral Ribeiro, que tem o morro Ferrabraz ao fundo.

\footnotetext{
9 O autor defende sua ideia utilizando como exemplo a cidade de Diamantina, em Minas Gerais. Segundo a análise feita pelo autor, o desenvolvimento do turismo na cidade fez com que a Igreja do Carmo se transformasse em um monumento (e não mais num lugar de oração), da mesma forma como a vida de Nossa Senhora do Carmo transformou-se em uma peça/cenário de interesse apenas comercial e turístico.
} 


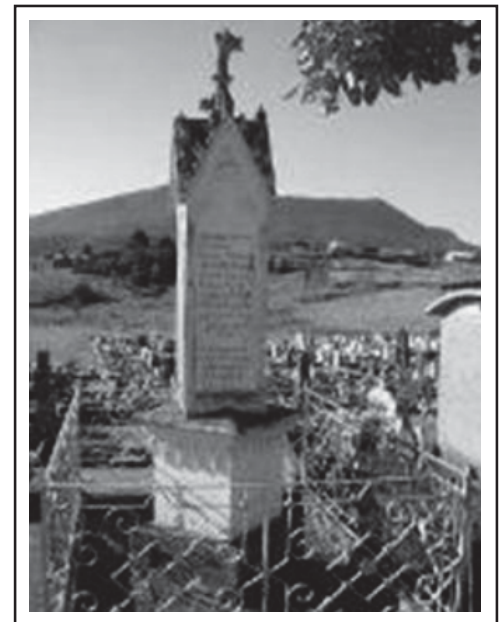

Figura 1: Túmulo do Cemitério de Amaral Ribeiro Fonte: Acervo do autor.

A sepultura, construída em 1874, foi a primeira representação monumental construída pela comunidade da Colônia Alemã para homenagear aqueles que haviam dado sua vida no combate aos Mucker. Esse monumento, localizado no cemitério do Amaral Ribeiro, em Sapiranga, procurou enaltecer a ação dos colonos mortos em combate, ao mesmo tempo que apontou os Mucker como seus assassinos. Na lápide da sepultura, encontramos uma homenagem, escrita em alemão, prestada aos homens que morreram em virtude dos supostos ataques dos Mucker e assinada pelos moradores da colônia. Como contraponto disso, temos o fato de Jacobina, juntamente com dezenas de Mucker assassinados, terem sido enterrados em uma vala comum nas proximidades do local onde ficava a residência de Jacobina e onde seria, décadas mais tarde, erguido o monumento em homenagem ao coronel Genuíno.

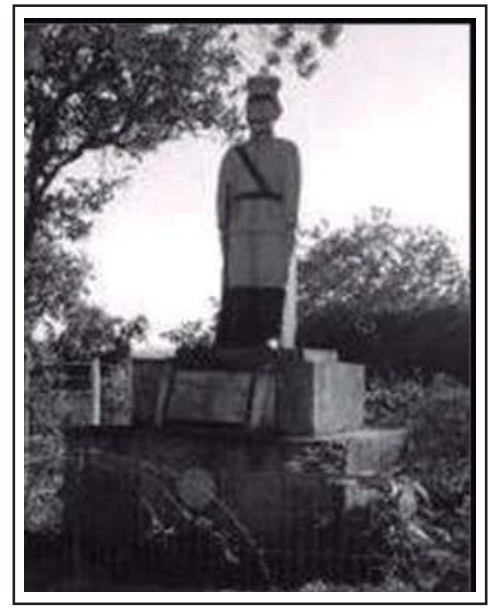

Além da sepultura, que é o primeiro lugar de memória construído sobre os Mucker, temos o Monumento alusivo ao Coronel Genuíno Sampaio e a Cruz de Jacobina, ambos localizados ao pé do morro Ferrabraz. A materialização do primeiro tinha como finalidade homenagear o Coronel Genuíno Sampaio, líder das tropas contrárias aos Mucker, que havia tombado em combate em 21 de julho de 1874. O monumento, construído em 1931 e inaugurado no ano seguinte, resultou da iniciativa de um morador de Sapiranga, Reinaldo Scherer, um jovem morador do morro Ferrabraz, que, através do seu gesto, transformaria Genuíno em um herói para a comunidade sapiranguense.

Figura 2: Monumento do Coronel Genuíno Sampaio Fonte: Acervo do autor. 
Naquele momento, a ideia do jovem morador da colônia era entendida pela comunidade como uma forma de tradução dos sentimentos coletivos, que assim se materializavam no projeto elaborado por Scherer, um colono que habitava as imediações do Ferrabraz.

Concomitantemente ao ato de inauguração do monumento, que contou com várias autoridades, registramos a entrega a alguém, cujo nome não é mencionado, mas que acreditamos se tratar de um vereador da Câmara de Vereadores de São Leopoldo, da Bíblia que supostamente Jacobina utilizava em suas pregações religiosas. Destacamos o simbolismo que reveste esse ato, que confiava às autoridades a guarda de um dos símbolos das crenças praticadas por Jacobina, impedindo, dessa forma, que o fanatismo fosse retomado.

Já a colocação de uma cruz no local em que Jacobina foi assassinada não ocorreu da mesma forma. Ao que tudo indica a colocação de uma cruz de madeira no local onde Jacobina e mais 16 adeptos foram mortos no dia 2 de agosto de 1874 deu-se apenas na década de 1910. A execução dessa obra, no entanto, não foi registrada através de fotografia, nem em documento escrito ou de qualquer ato oficial de inauguração, o que revela o aspecto não oficial, que procurava não despertar a atenção da comunidade em relação ao feito, uma vez que Jacobina não deveria ser evocada novamente nos sentimentos - e na memória - da comunidade.

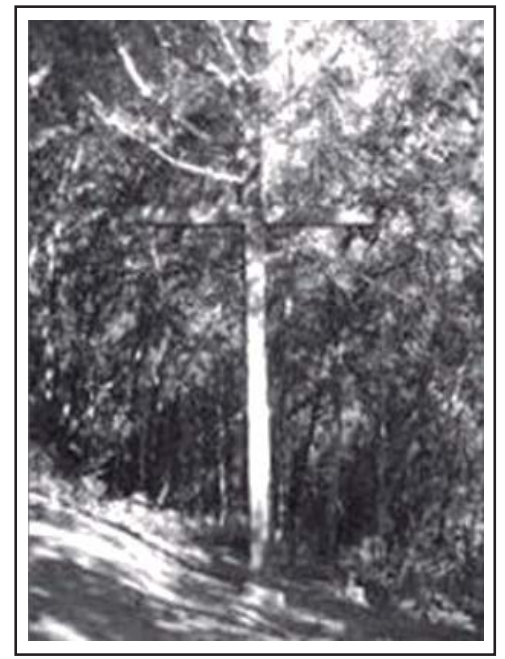

Figura 3: Cruz da Jacobina

Fonte: Acervo do autor.

Tomados como símbolos espaciais, tanto a cruz de Jacobina quanto o monumento alusivo ao Coronel Genuíno Sampaio foram erguidos, pela comunidade local, no cenário onde havia ocorrido o conflito, possuindo nítidos significados antagônicos. Essas visões polarizadas entre "o bem e o mal" foram responsáveis, em grande medida, pela construção do imaginário social sobre os Mucker.

Seria somente no início do século XXI que Jacobina teria um monumento construído em sua homenagem. O monumento erguido na praça (conhecida popularmente 
como "Praça da Jacobina"), localizada logo no acesso ao centro da cidade, foi construído em 2006, por iniciativa do vice-prefeito municipal, Fernando da Cunha, para homenagear Jacobina. Percebe-se que, naquele novo contexto, a líder dos Mucker revestia-se de um novo significado para a cidade, na medida em que ela foi a responsável pela projeção de Sapiranga em nível nacional, através do lançamento da obra cinematográfica $A$ Paixão de Jacobina, que, por sua vez, baseou-se na obra Videiras de Cristal, de Assis Brasil. A partir desse contexto, Jacobina encontrava-se como heroína, cujos princípios acabaram sendo transformados em motivo de celebração. Observando-se o monumento, encontramos, na sua base, uma inscrição com um breve perfil biográfico de Jacobina, de autoria de Daniel Gevehr, que apresenta uma breve biografia de Jacobina.

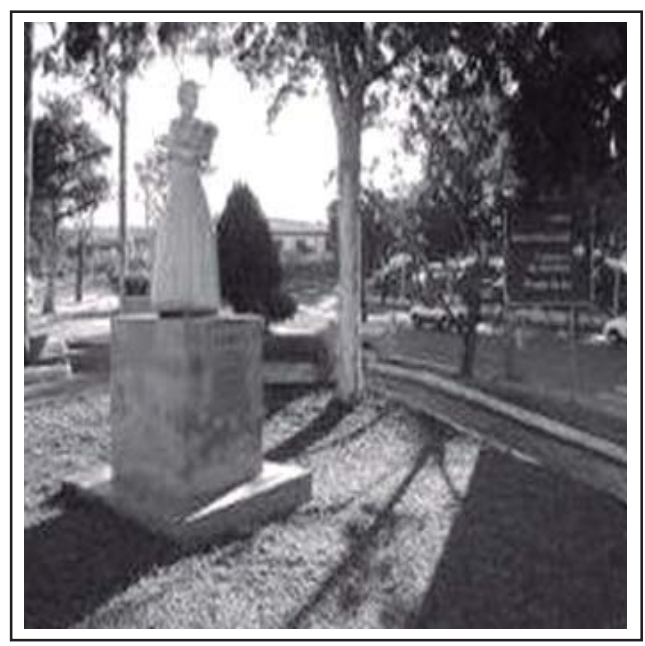

Figura 4: Monumento de Jacobina Fonte: Acervo do autor.

O imaginário, vale lembrar, tem como um de seus pontos de referência - e de lembrança - os lugares de memória, na expressão de Pierre Nora, para quem "a memória pendura-se em lugares assim como a história em acontecimentos" (1993, p. 25). Acreditamos que a sepultura do Cemitério do Amaral Ribeiro, a cruz e os monumentos de Genuíno e de Jacobina desempenham, enquanto lugares de memória, papel fundamental no processo de construção do imaginário sobre os Mucker. Além desses lugares, que nos remetem à lembrança dos Mucker, encontramos outros vários lugares - de memória - em Sapiranga que nos fazem lembrar do conflito, em um exercício cotidiano de relembrar os Mucker, os fatos e os personagens associados a eles. Exemplos concretos dessas iniciativas da comunidade, no sentido de manter viva a memória do tempo dos Mucker, tivemos em 1901, com a fundação do Clube 19 de Julho. Chamamos a atenção para a data de sua fundação, 19 de julho, dia e mês em que a casa de Jacobina foi destruída pelas forças imperiais no Ferrabraz. Cremos existir aí bem mais que uma simples coincidência, já que essa data era bastante significativa para a comunidade, por representar a data em que a "fortaleza do Ferrabraz" foi destruída. Embora não tenhamos fontes documentais ou testemunhos orais para corroborar nossa hipótese, impõe-se a 
possibilidade de vincularmos as duas datas do dia 19 de julho, a de 1874 e a de 1901.

Em 1937, ocorreu a criação e a inauguração do atual Instituto Estadual Coronel Genuíno Sampaio, localizado na zona central da cidade e, portanto, lugar de passagem e circulação da comunidade. A denominação da principal escola pública de Sapiranga foi realizada através do Decreto no 6702, de 27 de agosto de 1937. Assim o herói da luta contra os Mucker, cuja lembrança se mantinha viva na memória de seus moradores cotidianamente, tinha seu nome materializado em uma das mais importantes instituições da localidade. Também o CTG Pedro Serrano, fundado em 24 de junho de 1952, merece destaque nessa perspectiva de análise. Sua denominação aparece na documentação pesquisada desde 1961, fazendo com que todos relembrassem a atuação de Pedro Schmidt (conhecido pelos moradores da região à época do conflito como Pedro Serrano) como líder local das tropas de Genuíno no episódio do Ferrabraz, ao lado do Coronel, tendo Jacobina como rival. O principal aliado de Genuíno teve, dessa forma, seu nome registrado na memória da comunidade, sendo materializado em uma das instituições mais importantes do âmbito da vida cultural de seus moradores, que era o CTG.

Nesse contexto de mudanças, a municipalidade (criada através da emancipação de São Leopoldo em 1955) daria início a um processo - significativo - de construção de símbolos e nomeações de espaços da cidade, que inevitavelmente remeteram à história dos Mucker. Nomes de ruas, praças e avenidas que identificavam, em um primeiro momento apenas aqueles que lutaram contra os Mucker apareceram de forma evidente. Somente no final do século XX e principalmente a partir de 2002, com o lançamento do filme, a municipalidade tratou de promover a nomeação de diferentes espaços da cidade de Jacobina ou outras denominações que se associavam a fatos ou a personagens ligados diretamente ao lado dos Mucker. Era um novo tempo, em que a possibilidade de associar o nome de Jacobina com o desenvolvimento do turismo local apresentava-se como uma grande possibilidade.

O filme produzido em 2002 desempenhou, nesse sentido, papel preponderante na construção de uma nova imagem dos Mucker. Se, na década de 1990, a obra de Assis Brasil já havia provocado uma interpretação mais positiva sobre os Mucker, o filme A Paixão de Jacobina transformou os Mucker em heróis por terem lutado para defenderem seus ideais. Essa avaliação mais generosa não somente tornou os Mucker mais conhecidos como fez com que Sapiranga fosse conhecida regional e nacionalmente.

O próprio escritor gaúcho Assis Brasil (1997, p. 541), ao final de sua obra Videiras de Cristal, refere-se às obras que consultou, tecendo comentários sobre as interpretações que difundiram sobre o conflito dos Mucker:

Sempre persegui a ideia de escrever um romance sobre os muckers, um romance que, com maior ou menor fidelidade dos fatos, narrasse a trajetória pessoal de algumas personagens - reais ou fictícias - que tiveram parte de suas vidas ligada ao episódio do Ferrabrás. Nunca me passou pela cabeça escrever um romance histórico, muito menos uma 'história romanceada'. Assim, os puristas de plantão devem esquecer o propósito de conferir datas, nomes e eventos; talvez os encontrem subvertidos ou mascarados pela fantasia - não tão feérica - do autor. 
E continua Assis Brasil (1997, p. 541),

\begin{abstract}
Para escrever Videiras de Cristal utilizei algumas fontes primárias e outras secundárias. Entre as últimas, destaca-se a obra A nova face dos muckers, de Moacyr Domingues; com sua precisão factual e sua honestidade, foi mais do que tudo, um fascinante roteiro. Depois, houve outras obras: Conflito social no Brasil, de Janaína Amado, muito útil por sua perspectiva ideológica sobre o movimento; Os Muckers, do padre jesuíta Ambrósio Schupp, obra clássica e parcial; O Episódio do Ferrabrás, de Leopoldo Petry, que procurou repor algumas verdades; O messianismo no Brasil e no mundo, de Maria Isaura de Queirós, e ainda os artigos de Klaus Becker e Carlos H. Hunsche.
\end{abstract}

Assis Brasil deixa claro que procurou fazer uma história romanceada, mas que não descuidou de fazer uma criteriosa revisão bibliográfica e das fontes documentais. Isso permitiu que ele deixasse de esboçar - nesse comentário - sua crítica em relação à obra de Ambrósio Schupp, por ele qualificada como clássica e parcial, e de destacar positivamente as obras de Moacyr Domingues e de Janaína Amado, que serviram de base para a construção do enredo de sua obra.

O morro Ferrabraz, cenário do conflito Mucker, é apresentado na obra do autor, que traz a descrição de um lugar misterioso e de mata fechada, que dificultava a circulação das pessoas e o acesso até a casa de Jacobina. Acreditamos que a manutenção dessa descrição - já afirmada pelas obras publicadas até então - que privilegia a natureza selvagem do lugar deve ser compreendida como um recurso empregado pelo autor para despertar o imaginário do leitor e de envolvê-lo no ambiente natural do Ferrabraz e de suas belezas naturais.

Nesse sentido, tanto Videiras de Cristal quanto A Paixão de Jacobina valeram-se dessas primeiras descrições feitas do Ferrabraz, que ressaltam seu ambiente natural, associado ao mistério e marcado por belezas, que acabaram, inevitavelmente, despertando a curiosidade dos leitores e espectadores. Sem dúvida, esse aspecto foi bem mais explorado no filme, que trouxe cenas da área colonial do Ferrabraz, em que aparecem a mata nativa e as cachoeiras da região.

O filme A Paixão de Jacobina contou com a participação de atores globais, que acabaram atraindo curiosos durante as filmagens e, posteriormente, de interessados em conhecer os lugares nos quais os artistas da Rede Globo de TV haviam gravado as cenas do filme. As belezas naturais do lugar, associadas ao glamour dos artistas globais, acabaram atraindo muitas pessoas ao morro Ferrabraz e arredores. Assim, tanto a literatura quanto o cinema contribuíram de forma decisiva para a difusão da imagem do morro Ferrabraz como um lugar de muitas belezas ainda não exploradas.

Como já afirmamos, a literatura e o cinema tornaram-se responsáveis pela difusão de representações sobre o Ferrabraz e também sobre os Mucker. Deve-se, no entanto, ressaltar que se Assis Brasil procurou que o leitor fizesse uma "releitura" do conflito; o mesmo já não se pode afirmar sobre o filme de 2002. Se ambos descreveram o morro como um lugar belo e misterioso, o filme manteve e consagrou uma imagem fanatizada dos Mucker, como se constata nas cenas dos cultos e das pregações e, sobretudo, nas cenas em que Jacobina se despe e se entrega a Cristo e em que se deita, em meio à chuva, sobre o caixão de um dos seus adeptos. 
Deve-se, contudo, reconhecer que, apesar de reforçar representações negativas dos Mucker e de apresentar o Coronel Genuíno Sampaio como herói, o filme tem Jacobina como a personagem principal, além de contribuir para a divulgação do conflito e da região dos Mucker, que passaram a ser (re)conhecidos regional e nacionalmente.

Conhecidos em função da obra e do filme, os Mucker passaram a assumir uma nova representação, uma vez que poderiam servir aos interesses do município de projetar-se no roteiro turístico nacional, através da criação dos Caminhos de Jacobina, o que efetivamente ocorreu em $2001^{10}$. Esse projeto, que procurou desenvolver o turismo histórico-cultural ${ }^{11}$, resultou da parceria entre o Departamento de Turismo da Prefeitura Municipal de Sapiranga e o SEBRAE/RS, contemplando diferentes lugares de memória sobre os Mucker.

A ideia defendida pelo então Diretor do Departamento de Turismo da Prefeitura Municipal de Sapiranga, Sr. Luiz Roberto Prezzi, era "de ajudar as pessoas a conhecer mais sobre o episódio dos Mucker. Episódio esse que inspirou o autor Luiz Carlos Barreto no filme A Paixão de Jacobina"12.

No site Caminhos de Jacobina, encontramos, além da apresentação dos objetivos que levaram à criação desse roteiro de interesse histórico e cultural, os pontos turísticos a serem visitados na cidade:

- Cemitério Amaral Ribeiro - Mantém os túmulos de quatro moradores de Sapi-
ranga, mortos no conflito com os Mucker, na década de 1870 . A arte funerária
e as inscrições nas lápides do século XIX mostram traços culturais e religiosos
da comunidade. - Estátua do Cel. Genuíno Sampaio (local do futuro memorial Mucker) - Estátua erguida por colonos próximo à residência de Jacobina. Em 1874, nesse local, travaram-se duas batalhas entre os soldados do Coronel Genuíno Sampaio e o grupo de Jacobina.

- Cruz de Jacobina - Neste local, Jacobina e alguns do seu grupo se abrigaram para fugir do confronto com seus perseguidores. A cruz foi colocada no início do século XX, depois da visita de um dos remanescentes do confronto. Acredita-se que neste local Jacobina tenha sido assassinada.

- Locação "A Paixão de Jacobina" - A propriedade serviu como locação para o filme "A Paixão de Jacobina". Possui uma casa em estilo enxaimel, com mais de cem anos e reproduções dos personagens do filme, uma cozinha em estilo enxaimel, um galpão onde foi filmada a cena final e a trilha das Três Quedas com acesso a cascatas onde se pode tomar banho (PREFEITURA MUNICIPAL DE SAPIRANGA, 2013).

${ }^{10}$ O projeto nasceu da ideia do Diretor do Departamento de Turismo, Sr. Luiz Roberto Prezzi, durante a administração do prefeito Renato Delmar Molling, e tornou-se realidade a partir de 1999, quando se deu a parceria entre a Prefeitura Municipal de Sapiranga e o SEBRAE/RS. Em 2001, ocorreu a confecção e a colocação das placas projetadas para identificarem os pontos turísticos da cidade. Vale ressaltar que a execução do projeto se deu concomitantemente às filmagens de A Paixão de Jacobina.

11 "A questão da memória, da busca identitária e da apreensão do passado como patrimônio memorialístico apresenta-se como uma rica fronteira entre a História e o Turismo. A construção/invenção do passado como atrativo para quem viaja, parte de interpretações que são instrumentalmente inseridas no método da História, mas, também, por construções de caráter popular, lendário e mitológico" (MENESES, 2004. p. 15).

12 Esse objetivo encontra-se publicado no site oficial da Prefeitura Municipal de Sapiranga (2013), no link Caminhos de Jacobina, e também no fôlder produzido para divulgar o turismo da cidade. 
Além da apresentação dos quatro pontos turísticos que constituem os Caminhos de Jacobina, é oferecida uma breve explicação sobre os locais a serem percorridos. Constata-se, no entanto, que a página editada pela Prefeitura Municipal não oferece maiores informações sobre a história do conflito, restringindo-se a um breve resumo:

\begin{abstract}
O Episódio dos Mucker tratou-se de um conflito entre os colonos alemães, que ocorreu no século XIX, no Morro Ferrabraz. Jacobina e João Jorge Mauer se conheceram em Hamburgo Velho, na metade do século XIX. Casaram-se e mudaram-se para Leoner-Hof (como era denominada Sapiranga). Jacobina sofria de ataques epiléticos, desde criança, o que fazia com que ela fosse vista como vítima de um transtorno do sistema nervoso, agravados por leituras de natureza religiosa. Além disso, Jacobina auxiliava o marido no curandeirismo. Naquela época, os médicos eram escassos. Então, as pessoas apelavam para os curandeiros. Aos poucos, Jacobina misturava a religião com o atendimento aos doentes, através de leituras de passagens bíblicas para os pacientes. Logo, ela tornava-se famosa por suas meditações milagrosas. Os adversários de Jacobina, preocupados com os acontecimentos no Ferrabraz, realizaram um abaixo-assinado, levando a imprensa da época a tomar partido contra Jacobina. Iniciou-se então a guerra. Formaram pequenos grupos e saíram para incendiar casas comerciais, gerando mortes de crianças e adultos. O combate final ocorreu em dois de agosto de 1874 (PREFEITURA MUNICIPAL DE SAPIRANGA, 2013).
\end{abstract}

Outro meio de divulgação dos Caminhos de Jacobina é um material elaborado pelas prefeituras dos municípios do Vale do Sinos em parceria com o SEBRAE. A ideia surgiu no início desta década, quando os municípios da região descobriram seu potencial turístico. Daí nasceu a necessidade de se organizar um material que divulgasse os atrativos dos municípios da região de imigração alemã.

O fôlder produzido foi intitulado Caminhos do Vale: Rota turística e está organizado de forma que cada um dos seis municípios envolvidos no projeto mostre sua história e os principais pontos turísticos. Na parte intitulada Conheça Sapiranga, encontramos, na introdução, o subtítulo Caminhos de Jacobina, em que é apresentada uma breve síntese: "Sapiranga é um espaço atraente, procurado por muitas pessoas que desejam manter o contato com a natureza próxima dos centros urbanos e visitar o roteiro Caminhos de Jacobina. Este roteiro pode ajudar você a conhecer mais sobre o episódio dos Mucker" (PREFEITURA MUNICIPAL DE SAPIRANGA, 2013). Logo abaixo do texto da apresentação, são identificados os pontos turísticos dos Caminhos de Jacobina, da mesma forma como os encontramos no site citado anteriormente.

Faz parte do fôlder a apresentação de um roteiro turístico que prevê a visitação a vários lugares da cidade. Por meio dele, os visitantes podem conhecer a Casa do Turista, a casa construída em 1845 em estilo enxaimel, a praça das rosas, o museu municipal, o morro Ferrabraz, a casa do produtor, o monumento ao imigrante, construído em 1974 para marcar o sesquicentenário da imigração alemã, o Centro Municipal de Cultura, as igrejas do centro da cidade e a praça da Bandeira. São apresentados, ainda, campings e balneários localizados na zona rural, além de cafés e restaurantes que podem ser desfrutados pelos turistas.

Um elemento que merece ser destacado na apresentação do roteiro turístico é a justificativa dada para enaltecer o desenvolvimento do município. De forma muito evidente, estabelece uma associação entre progresso econômico e imigração alemã, ao destacar: 
O vigor da colonização alemã sempre rendeu as melhores histórias e serviu para fundamentar a cultura de Sapiranga. Imagine um lugar que reúne grandes áreas nativas, história preservada e uma forte cultura germânica. Sapiranga atrai aqueles que desejam descansar em sítios de lazer, cavalgar, conhecer as antigas edificações dos colonizadores da região, apreciadas durante o 'city tour' (PREFEITURA MUNICIPAL DE SAPIRANGA, 2013).

Outro aspecto que nos chama a atenção em nosso estudo é o logotipo criado para identificar e divulgar para os visitantes os Caminhos de Jacobina. Esse tem como imagem o busto de Jacobina vista de perfil, ao qual é justaposto o título Caminhos de Jacobina. Chama-nos a atenção a evidência dada à líder dos Mucker. Sua imagem estilizada é empregada simbolicamente para fomentar o turismo da região, e seu nome é transformado em ícone para atrair a atenção dos visitantes.

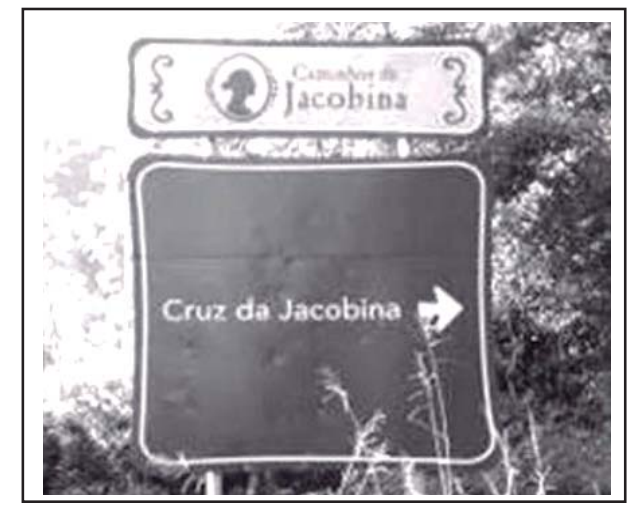

Figura 5: Placa Indicativa dos Caminhos de Jacobina Fonte: Acervo do autor.

Nos Caminhos de Jacobina, ressaltamos a importância do Museu Municipal de Sapiranga ${ }^{13}$, inaugurado em 1996. O museu localiza-se na área central da cidade, no prédio da antiga estação férrea, inaugurada em 1903 e desativada em 1964. Nele encontramos parte da cultura material e imateria ${ }^{14}$ dos sapiranguenses, que remonta à época

\footnotetext{
${ }^{13}$ Para o historiador José Newton Coelho Meneses, "o museu é um lugar que toma como base três valores indissociáveis: o valor identitário (que considera o patrimônio como gerador constante de construção de imagens, significados e identidades), o valor econômico (que toma o patrimônio como gerador de oportunidades econômicas) e o valor social (que defende que os projetos interpretativos devem gerar a melhoria da qualidade de vida da comunidade que administra esse patrimônio)" (MENESES, 2004, p. 75).

$14 \mathrm{O}$ conceito de cultura material e imaterial empregado no artigo está de acordo também com os estudos realizados por José Newton Coelho Meneses. Para ele (2004, p. 24): “Têm-se colocado como distintos no conceito de patrimônio material e o que se configuraria como um patrimônio imaterial. O primeiro seria o conjunto das construç̃es físicas do homem na sua relação com o meio ambiente para o atendimento de suas necessidades práticas. O segundo conjunto agruparia as construções mentais e os valores culturais configurados em signos e significados diversos. Essa dicotomia não se sustenta nem didaticamente, posto que a inteligibilidade de uma manifestação cultural só tem sentido se percebida em conjunto. O universo material media sentidos, valores, significados. Separá-los em sua compreensão, buscando uma compartimentação irreal da vida, seria destruir a possibilidade de apreensão da construção de uma cultura".
} 
dos imigrantes alemães (e dos Mucker). Mantido pela Prefeitura Municipal, o museu é um lugar de memória para os sapiranguenses e possui um importante acervo, constituído por móveis, utensílios diversos, vestimentas, livros, revistas, jornais, documentos e um rico acervo fotográfico.

O museu consiste em lugar de referência para os visitantes que buscam conhecer a cultura e as tradições herdadas dos imigrantes alemães, contando com significativo acervo bibliográfico ${ }^{15}$ sobre os Mucker. $\mathrm{O}$ museu, no entanto, não possui nenhum outro acervo associado aos Mucker, o que causa, muitas vezes, surpresa aos visitantes ${ }^{16}$.



Figura 6: Placa indicativa dos Caminhos de Jacobina Fonte: Acervo do autor.

Observamos, na Figura 6, a placa colocada em frente ao Museu Municipal de Sapiranga. Nela encontramos a informação sobre a direção de vários lugares turísticos. Isso se dá em razão de que o museu serve, na maioria das vezes, de ponto de chegada dos turistas na cidade e de ponto de partida para o roteiro turístico dos Caminhos de Jacobina. Partindo do museu e seguindo pela Avenida Vinte de Setembro (antiga estrada de ferro), os visitantes chegam aos diversos lugares de memória e pontos turísticos, que assim constituem o roteiro turístico da cidade.

15 Encontram-se no Museu reunidas as principais obras publicadas sobre os Mucker, além dos trabalhos acadêmicos desenvolvidos por vários pesquisadores. Soma-se a esse acervo bibliográfico a coleção de jornais $O$ Ferrabraz, nos quais foram publicados diversos artigos sobre os Mucker, no período de 1949 à 1960.

${ }_{16}$ De acordo com os funcionários do Museu Municipal, são constantes os questionamentos feitos pelos visitantes do Museu sobre a inexistência de armas, de Bíblias, de roupas ou de utensílios utilizados pelos Mucker no Museu. 
Chama a atenção que, ao lado da cruz de Jacobina - local que simboliza o lugar em que ela foi assassinada em 1874 -, também encontramos uma placa que apresenta aos visitantes um breve resumo sobre o conflito e enfatiza o papel assumido por Jacobina na história do conflito.



Figura 7: Placa Indicativa dos Caminhos de Jacobina Fonte: Acervo do autor.

O texto apresentado não teve a participação de nenhum historiador em sua elaboração. Ele chama a atenção por reconstituir um cenário marcado por armas de guerra, fogo e gritos, recriando o ambiente no qual Jacobina foi assassinada. Ao descrever Jacobina, ele a apresenta, mais uma vez, como líder de um grupo de fanáticos religiosos e como reencarnação de Cristo. Já os Mucker são apresentados como uma pequena comunidade de fanáticos religiosos que se formou ao pé do morro Ferrabrás. O ambiente de mistério que envolvia o morro Ferrabraz é recriado através de expressões como gritos terríveis, triste episódio, profundo espírito religioso e fanáticos religiosos, reforçando, ainda, a associação entre mistério e fanatismo.

No monumento inaugurado em 1932 para homenagear Genuíno, encontramos uma placa que apresenta uma breve biografia do personagem. Genuíno é descrito como o chefe das operações militares que dizimaram os Mucker. Chama-nos a atenção a justificativa dada para o fato de este monumento se encontrar no mesmo lugar em que anteriormente se localizava a casa dos Maurer. Afinal, aquele era o lugar, segundo a interpretação apresentada, onde Jacobina e seu marido realizavam sua práticas religiosas e de cura, motivo que teria deflagrado o conflito no século XIX. 


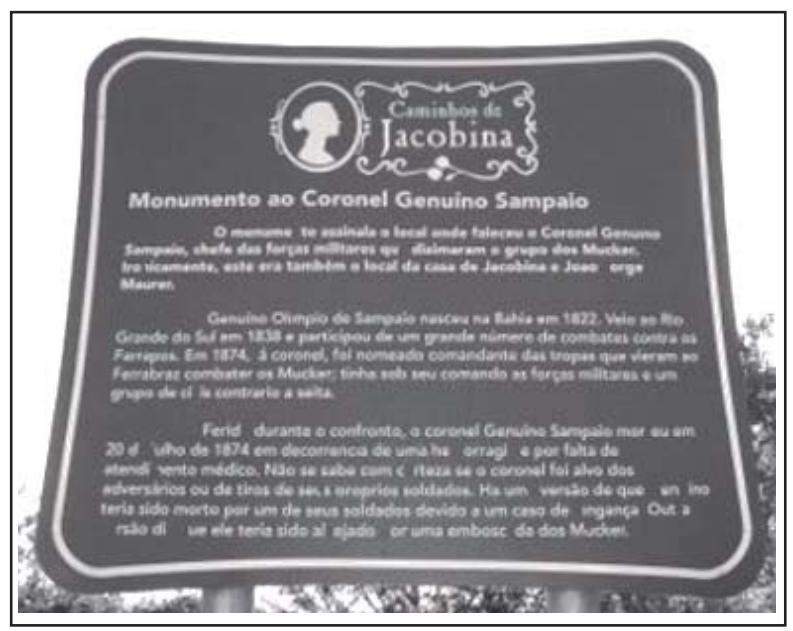

Figura 8: Placa Indicativa dos Caminhos de Jacobina Fonte: Acervo do autor.

Temos ainda, como parte importante dos Caminhos de Jacobina, o lugar conhecido como Colônia de Jacobina, sendo esse um dos pontos turísticos mais explorados do roteiro. O lugar, que serviu de cenário para as filmagens do filme $A$ Paixão de Jacobina, está situado no alto do morro Ferrabraz, na localidade de Picada Schneider, zona rural de Sapiranga, e apresenta aos visitantes o cenário construído pela equipe de filmagens para a produção de $A$ Paixão de Jacobina.

Entre os diferentes lugares de memória construídos sobre os Mucker, encontramos ainda a Pedra Branca de Jacobina. Ela destaca-se na paisagem, atraindo um bom número de turistas e a atenção dos que sobem o morro para a prática do vôo livre. Na placa que identifica a Escadaria na Pedra Branca de Jacobina, encontramos duas inscrições bastante significativas, que procuram explicar aos visitantes o significado do lugar.

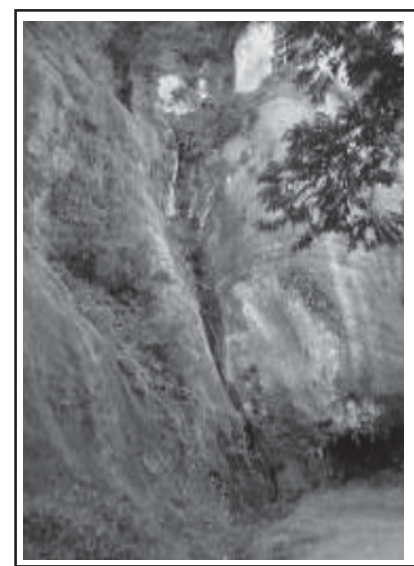

Figura 9: Pedra Branca

Fonte: Acervo do autor.

É informado na placa que o lugar teria abrigado Jacobina e seus adeptos após o ataque sofrido em 19 de julho e do qual resultou o incêndio de sua casa.

É preciso, contudo, esclarecer que essa informação não procede, já que o local escolhido pelos Mucker para se esconderem das forças imperiais foi aquele onde encontramos a cruz de Jacobina, e não a caverna como menciona a placa.

A caverna existente no morro Ferrabraz é, também, constantemente associada pelos moradores de Sapiranga ao lugar em que os Mucker, a mando de Jacobina, guardavam armas, mantimentos e escondiam-se em situações de ataque. 
Percebe-se, nessas placas, a veiculação de informações sobre a história e também sobre os lugares associados a ela, que nem sempre se mostram fiéis àquilo que a historiografia ou até mesmo a documentação existentes nos permitem afirmar como reais.

Além desses lugares de memória sobre os Mucker, temos ainda a Colônia de Jacobina, um dos pontos turísticos mais explorados do roteiro dos Caminhos de Jacobina. 0 lugar, que serviu de cenário para as filmagens do filme $A$ Paixão de Jacobina, está situado no alto do morro Ferrabraz, na localidade de Picada Schneider, zona rural de Sapiranga. A Colônia de Jacobina é uma propriedade particular, cujos proprietários, moradores de Sapiranga, aproveitam o cenário construído pela equipe de filmagens para receber os visitantes interessados em conhecer o local em que foram produzidas partes das cenas exibidas no filme.

Através do material de divulgação produzido pela Prefeitura Municipal de Sapiranga, a Colônia Jacobina, localizada na Picada Schneider, é descrita como um dos pontos da rota turística municipal e que serviu de locação para o filme A Paixão de Jacobina. E ainda, que a propriedade possui uma casa centenária, em estilo enxaimel, com móveis originais e utensílios domésticos e decorativos conservados, com sala, quarto, cozinha e escritório preservados exatamente como foram vistos nas telas de cinema. $\mathrm{O}$ galpão construído pela equipe cinematográfica para representar o templo dos Mucker, que foi incendiado no final das filmagens, foi mantido em perfeitas condições e ainda com as marcas do fogo. O material informa, também, que ao lado da construção tem um cemitério cênico que completa a atmosfera onde ocorreu o romance.

O texto de divulgação revela a forte vinculação do lugar com as filmagens realizadas em 2002 pela equipe dirigida por Fábio Barreto, não negando seu caráter cênico. Foi a partir do filme que a Colônia Jacobina tornou-se conhecida, não apenas pela comunidade sapiranguense, mas do público em geral, transformando-a em um lugar turístico.

As construções feitas pela equipe, como o galpão e o cemitério, somadas à casa em estilo enxaimel já existente na propriedade, procuraram recriar o ambiente em que teriam vivido os Mucker. Cabe, no entanto, esclarecer que o local onde se encontra a Colônia de Jacobina fica bastante distante do lugar - o pé do morro Ferrabraz - onde se localizava a residência de Jacobina e João Jorge Maurer. Esse elemento, embora evidente, é, muitas vezes, motivo de confusão, já que algumas pessoas acreditam que os Mucker reuniam-se na atual Colônia de Jacobina e não no lugar localizado ao pé do morro Ferrabraz ${ }^{17}$.

Percorrendo os lugares de memória construídos sobre os Mucker em Sapiranga, podemos observar como a história do conflito sofreu, efetivamente, um significativo processo de ressignificação.

Através dele, os Mucker foram reavaliados e tiveram sua imagem associada à de lutadores. Se, até pouco tempo atrás, o imaginário sobre os Mucker os remetia a um ambiente de fanatismo e rebeldia, nos dias atuais, eles são tidos como verdadeiros precursores na luta e defesa dos interesses da comunidade.

\footnotetext{
${ }^{17}$ Lembramos que o lugar onde atualmente encontramos o monumento construído em homenagem ao Coronel Genuíno Sampaio é o mesmo onde se localizava a residência de Jacobina e João Jorge Maurer. 


\section{CONSIDERAÇÕES FINAIS}

Finalmente, ao identificarmos os lugares de memória dos Mucker, chegamos a algumas constatações importantes, que apontam para as razões de sua criação em diferentes momentos da história. Jacobina Maurer e Genuíno Sampaio foram os personagens eleitos pela comunidade para representarem, respectivamente, os Mucker e seus combatentes. Se, em um primeiro momento, Jacobina é representada como a líder dos Mucker e associada a condutas condenáveis, Genuíno é representado como herói, ao ter dado sua vida ao combatê-los. Já em um segundo momento, especialmente a partir da década de 1990, Jacobina passa a ser apresentada como uma heroína, com características morais que a enalteciam, ao mesmo tempo que Genuíno tem sua atuação reavaliada, sendo colocado como personagem coadjuvante.

A partir das últimas décadas do século $X X$, percebe-se um novo olhar sobre a questão. Marcos significativos dessas novas abordagens são, sem dúvida, os apelos comercial e turístico de que foram alvo esses lugares de memória e a produção literária e cinematográfica, que muito contribuíram para que Jacobina fosse alçada à condição de protagonista e líder social e, especialmente, desempenhasse a função de guia turística pelos Caminhos de Jacobina.

Se, no passado, a líder dos Mucker era associada pela comunidade a uma mancha que borrava sua imagem, a partir de então, ela será compreendida como a mulher que motiva o seu orgulho. É nessa dinâmica das representações e da construção de imagens que Genuíno, tido como herói no passado por ter apaziguando a colônia, terá sua imagem confrontada com a de Jacobina, transformando-se em um personagem secundário. Diante disso, é possível afirmar que, no início do século XXI, Jacobina saiu vitoriosa na luta pelas representações, sendo celebrada pelos e nos Caminhos de Jacobina e, assim, associada a um possível potencial do desenvolvimento econômico regional, o que torna, a partir do início do século XXI, sua imagem positiva, representando a ideia de progresso e desenvolvimento da região.

A construção da imagem da líder dos Mucker, entretanto, continua promovendo intensos debates, na medida em que Jacobina não tem um corpo, um rosto ou até mesmo vestígios deixados por ela que nos permitem afirmar como era, de fato, a líder dos Mucker. Essa questão pode ser percebida nas tentativas de se recriar Jacobina através de diversas pinturas ou até mesmo da criação de estereótipos associados a atrizes globais - como foi o caso de Letícia Spiller - ainda que sem muitas referências concretas de como era fisicamente a líder dos Mucker. A associação de Jacobina ao ambiente religioso e a também a flor símbolo de Sapiranga, a rosa, são bons exemplos de como ela é representada.

Finalmente, percebemos que os diferentes elementos que constituem a dinâmica de construção das imagens e das representações sobre os Mucker - e de forma mais expressiva - sobre Jacobina nos permitem compreender como esse episódio, ocorrido no final do século XIX na Antiga Colônia Alemã de São Leopoldo (RS), provocou e, ainda continua provocando, intenso debate sobre as diferentes "faces" de um dos capítulos mais significativos da história da imigração alemã no sul do Brasil. A materialidade - e também 
a imaterialidade apresentada na subjetividade que esses elementos produzem no imaginário social - exposta nos lugares de memória da cidade de Sapiranga reafirma essa percepção, na medida em que, percorrendo "Os Caminhos de Jacobina", temos a possibilidade de compreender como uma coletividade pode re(afirmar) suas sensibilidades. Essas, muitas vezes, se materializam nos lugares produzidos historicamente, que atendem, por sua vez, aos interesses dos diferentes grupos que as produzem.

\section{REFERÊNCIAS}

ASSIS BRASIL, Luiz Antonio de. Videiras de cristal: o romance dos Muckers. 5. ed. Porto Alegre: Mercado Aberto, 1997.

CARVALHO, José Murilo de. A formação das almas: o imaginário da República no Brasil. São Paulo: Cia. das Letras, 1990.

CHOAY, Françoise. A alegoria do patrimônio. São Paulo: Unesp, 2001.

DOMINGUES, Moacyr. A Nova Face dos Muckers. São Leopoldo: Rotermund, 1977.

HALBWACHS, Maurice. A memória coletiva. São Paulo: Centauro, 2004.

JODELET, Denise (Org.) As representações sociais. Rio de Janeiro: EDUERJ, 2001.

MENESES, José Newton Coelho de. História e Turismo Cultural. Belo Horizonte: Autêntica, 2004.

NORA, Pierre. Entre memória e história. A problemática dos lugares. Projeto História. Revista do Programa de Pós-graduação em História e do Departamento de História PUCSP, n. 10, p. 7-28, dez. 1993.

PEDRO, Joana Maria. Mulheres do sul. In: DEL PRIORI, Mary (Org). História das mulheres no Brasil. 7. ed. São Paulo: Contexto, 2004.

PESAVENTO, Sandra Jatahy. O imaginário da cidade. Visões literárias do urbano. Paris, Rio de Janeiro, Porto Alegre. Porto Alegre: UFRGS, 2002.

PREFEITURA MUNICIPAL DE SAPIRANGA. Caminhos de Jacobina. Disponível em: <www.sapiranga.rs.gov.br>. Acesso em: 23 jul. 2013. 